\title{
Author Correction: A quantitative method for proteome reallocation using minimal regulatory interventions
}

Gustavo Lastiri-Pancardo, Jonathan S. Mercado-Hernández, Juhyun Kim, José I. Jiménez (D) and José Utrilla (D)

Correction to: Nature Chemical Biology https://doi.org/10.1038/s41589-020-0593-y, published online 13 July 2020

In the version of this Article originally published, the last sentence of the Acknowledgements section was missing information. The sentence "G.L.P. held a CONACyT scholarship, registration number 434655" should now read "G.L.P. acknowledges the Programa de Doctorado en Ciencias Biomédicas, Universidad Nacional Autónoma de México (UNAM), and the PhD scholarship 434655 from CONACyT." The error has been corrected in the HTML and PDF versions of the paper.

Published online: 9 September 2020

https://doi.org/10.1038/s41589-020-00666-6

(c) The Author(s), under exclusive licence to Springer Nature America, Inc. 2020 